\title{
Simbolización y filosofía en la psicopatología de Karl Jaspers.
}

\author{
Symbolization and Philosophy \\ in Karl Jaspers' Psychopathology.
}

\author{
FRANCISCO RODRÍGUEZ VALLS \\ Universidad de Sevilla
}

Recibido: 05-12-2018

Aceptado: 17-12-2018

\section{RESUMEN}

La Allgemeine Psychopatologie de Karl Jaspers es una obra clave del pensamiento del siglo $\mathrm{XX}$. Une de forma interdisciplinar la medicina, la psicología y la filosofía existencial. De entre los conceptos que trata, este ensayo verá la función del concepto de símbolo y a través de él la función de la Filosofía como guía de la Psiquiatría y de la Psicopatología en general. En la Psiquiatría contemporánea cada vez se da más importancia a la «simbolización» como concepto clave bajo el que el sujeto humano interpreta su existencia. El símbolo es un esquema de realidad que se construye y reconstruye continuamente a través de las experiencias del ser humano. Puede decirse entonces que, a través del símbolo, el ser humano construye su mundo. En esa construcción, la Filosofía puede suponer una ayuda si se plantea como «ansia de saber»o, en su lugar, como una rémora si se presenta como una totalidad omnicomprehensiva inflexible bajo la que subsumen todas las experiencias de la vida.

\section{PALABRAS CLAVE}

SIMBOLIZACIÓN, FILOSOFÍA, PSICOPATOLOGÍA, JASPERS.

*El presente texto es uno de los resultados del proyecto «La psicopatología de Karl Jaspers: génesis y actualidad de la analítica existencial». Ha sido financiado parcialmente con una ayuda para estancias breves en el extranjero del VI Plan Propio de Investigación de la Universidad de Sevilla. La estancia se desarrolló durante los meses de Abril y Mayo de 2018 en el Instituto de Filosofía de la Universidad Técnica de Berlín.

(C) Contrastes. Revista Internacional de Filosofia, vol. XXIII-Nº3 (2018), pp. 109-119. ISSN: 1136-4076

Departamento de Filosofía, Universidad de Málaga, Facultad de Filosofía y Letras Campus de Teatinos, E-29071 Málaga (España) 


\begin{abstract}
Karl Jaspers' Allgemeine Psychopatologie is a key book in twentieth century thought. He gets together in an interdisciplinary way Medicine, Psychology and Existential Philosophy. Among all their concepts this paper deals with the one of symbol and through it the role of Philosophy as a guide for Psychiatry and, in general terms, for Psychopathology. In nowadays Psychiatry «symbolization» is a more and more key concept under which human subject makes and interpretation of his/her existence. Symbol is a scheme of reality built and rebuilt once and once again through all the experiences of human being. It can be said that because of symbol human being «builds the world». Philosophy can be a help for that construction if appears as a «wish of wisdom» or, instead of that, as a lack if appears as a «theory of everything» to subsume under itself all the experiences of life.
\end{abstract}

KEYWORDS

SYMBOLIZATION, PHILOSOPHY, PSYCHOPATHOLOGY, JASPERS.

\title{
INTRODUCCIÓN
}

La Allgemeine Psychopatologie de Karl Jaspers, médico, psiquiatra, filósofo, puede sin duda pasar por ser una de las obras fundamentales de la primera mitad del siglo XX. Desde 1913, fecha de la publicación de la primera edición, hasta 1946, año en la que se publica la última corregida por el autor, pasan más de treinta años durante los cuales desarrolla gran parte de su magnífica y monumental actividad intelectual. El interés por este tema le acompañó siempre. La pregunta que deseo responder en este ensayo es la siguiente: ¿es la comprensión de la psicopatología una ayuda para la antropología filosófica o, más bien, una visión que pretenda ser completa del ser humano puede prescindir de ella en tanto que, podría pensarse, solo estudiaría rarezas y disfunciones que estadísticamente no afectan a una población muy elevada?

Tomo como opción la necesidad de estudiarla puesto que uno de los peligros que encierra una antropología mal planteada es el de reducir el ser humano a un conjunto de conceptos elaborados «a priori». Ello ha llevado a tanta exclusión trágica de lo humano (eurocentrismo, racismo, machismo, nacionalismo) que la historia la ha hecho inviable. Scheler nos advierte de ello en su obra de 1928 Die Stellung der Mensch in Kosmos al entender la Antropología Filosófica como una síntesis en el plano de la Filosofía de los datos aportados por las ciencias empíricas que se ocupan de lo humano. Si eso es así, y también lo es que «nada de lo humano nos es ajeno», no resultará extraño que pueda aprovechar también el lado obscuro de las existencias desestructuradas para dar pasos hacia adelante en la comprensión de su objeto. No se trata, como ocurrió en el caso de Freud, de entender y recomponer la estructura de la subjetividad sana desde la enferma, sino de aprovechar lo desestructurado para 
verlo como posibilidad de lo humano que requiere cura o, si no puede curarse, necesita cuidado. La psicopatología es uno de los botones de muestra de la plausibilidad de una antropología bien realizada en tanto que despliega todas las posibilidades de la humanidad. La observa en toda su exhibición biográfica y de autoconstrucción y no con la rigidez de una roca. Una de las formas de llevar lo humano a su límite es aprehenderlo también en su enfermar. No basta con hacer una antropología de lo normal y de lo maduro, hay que verlo también en sus patologías y en su evolución completa desde el nacimiento hasta la muerte.

\section{NORMALIDAD Y ANORMALIDAD EN LO HUMANO}

Una de las cuestiones clave que recorre la ciencia social del siglo XX por entero es la de qué se entiende por individuo normal o anormal. Parece lógico que, cuando se ha universalizado demasiado y estandarizado en exceso un ámbito de realidad, lo diferente aparezca como deficiente y monstruoso más que como distinto. Solo recientemente hemos recuperado - tras un gran esfuerzo de evaluación histórica- que la excelencia humana tiene muchas formas de realizarse. Es verdad que eso supone un debilitamiento de la noción de substancia y un fortalecimiento de la categoría de relación. Pero ese cambio ontológico parece que se ajusta más a la realidad humana y a la historia que la rigidez con la que se entendía anteriormente al no contar con el tiempo como factor clave de la constitución de lo humano de forma biográfica. Si, repitiéndonos, nada de lo humano nos es ajeno, tampoco lo será lo que se aparte de una norma que difícilmente podrá recoger a todo lo que entra en la categoría de humanidad. Hay que ganar el concepto de que lo distinto no constituye una anormalidad sino una realización diferente de lo humano. Pero ello no significa aceptar cualquier constitución fáctica o posible como normal. El problema «qua» problema, el problema que engendra sentido plantear en nuestra temática, se constituye de hecho como tal cuando el ser humano se convierte en peligroso para él mismo o para los demás. Si el ser humano se caracteriza por su sociabilidad, es decir y para evitar malentendidos, si solo se constituye como tal ser humano en un entorno socio-cultural y está en gran medida en deuda con ese entorno, parece que un criterio para diferenciar entre lo distinto y lo anormal es cuando la condición propia o la del otro causa sufrimiento individual y social. Es cierto que es difícil separar lo que es propio de un entorno sociológico de lo que es una ontología de la personalidad, pero considero que en esas ocasiones tenemos que distinguir viendo caso por caso por el hecho de que toda historia clínica se inscribe en una biografía. Y es que, en el complejo caso de lo humano, hablar en general es prácticamente atentar contra su dignidad.

La estructura de la subjetividad tiene muchas maneras de conformarse y de consolidarse. Al proceso mediante el cual esa estructura madura y se 
hace auténtica, o no lo hace y se torna inauténtica, se le conoce con el nombre de existencia. No queremos asignar a los términos «auténtica»o «inauténtica» referidos a la existencia un sentido heideggeriano; solamente queremos dar a entender con ello el hecho de que la personalidad puede construirse de acuerdo con valores conscientes y positivos o de forma inconsciente $y$, en el segundo sentido, no se hace responsable de sí misma y es mucho más fácil la posibilidad de su desestructuración cuando media -ya que tarde o temprano aparece, o al menos es deseable que lo haga- la autoconciencia. El entramado de la subjetividad cuenta con elementos orgánicos, psíquicos y espirituales o valorativos y a cada uno de esos tres -separadamente o en su conjunto- puede achacársele la causa de la normalidad o de la anormalidad. Tampoco queremos hablar en términos estadísticos o de términos medios. Jaspers deja bien clara la diferencia entre subjetividad ideal y subjetividad referida a un término medio sociológico. En cualquier caso, si un desorden orgánico, psíquico o espiritual causa sufrimiento en algún sentido, habrá que tratarlo. Habrá que investigar sus causas reales o fingidas. Y, si no puede ser curado, habrá que cuidar al sujeto de múltiples formas, tantas como la sociedad en la que habita haya descubierto hasta la fecha. Hay, independientemente de que se deba a una causa orgánica, psíquica o espiritual o que responda a una ilusión, que determinar las causas de ese sufrimiento para tratarlas. Ese argumento puede derivar en un criterio pragmático - que se ha usado con mucha frecuencia- que da prioridad al bienestar antes que a la teoría, pero considero que ese es también un criterio válido ya que cuando el dolor acucia hay que reducirlo hasta que sea soportable; y eso antes de discutir sobre si es formativo o no lo es para la persona tenerlo, padecerlo, enfrentarse a él o rehuirlo. Cada profesional engendrará su propio criterio y establecerá cuánto dolor puede permitírsele soportar a un paciente antes de que se torne en indignidad. Aunque lo ideal sería establecer protocolos comunes contando con las variaciones que existen dentro de la propia categoría de humano.

\section{LOS PROCESOS DE SIMBOLIZACIÓN}

El hecho es que para constituir su subjetividad desde elementos dados (orgánicos, psíquicos y valorativos o espirituales), el ser humano debe interpretar cognoscitivamente -tanto consciente como inconscientemente- las experiencias que recibe y eso lo hace construyendo sentidos de realidad a los que podemos denominar esquemas simbólicos o, sin más, símbolos. Un símbolo es un esquema de realidad, una representación esquemática de la realidad. El sujeto se abre a ella pero no puede abarcarla en su totalidad. El sujeto tiene que simplificarla en la medida de sus posibilidades para aprehenderla. Son tantos los estímulos, las circunstancias, los ambientes posibles, que el sujeto realiza un diálogo con ellos. Su contingencia hace que no pueda reconstruirlos de manera completa y 
deba simplificar. Esas singularidades simplificadas son las que sirven de fuente para la construcción de su experiencia. A este tipo de simbolización, a cómo expresa esas singularidades, la psicopatología contemporánea da cada vez más importancia para ver el tipo de realidad que el sujeto está viviendo. Esas «vivencias»-término tan querido para la fenomenología- serán las fuentes de la unificación de las siguientes experiencias y, en consecuencia, del más que probable futuro existencial del sujeto: lo posterior se construye sobre lo anterior y según se haya construido lo anterior se percibirán pistas de cómo aparezca lo normal o lo anormal en lo humano. La realidad como tal es tan amplia que no puede ser abarcada por el sujeto. Tiene que ser objeto de una interpretación que, en el conocimiento científico, tiende a ser lo más completa posible pero que siempre quedará en una... búsqueda sin término. Originariamente los procesos de percepción y representación estaban hechos para mantener al sujeto sobreviviendo en la existencia. Esos son los fundamentos evolutivos del conocimiento de la realidad: la vida tiene como fin la supervivencia y lo que es útil para ella y no la verdad en sí misma. Pero, cuando aparece el sujeto humano, los límites se extienden hacia la contemplación de la realidad en sí y hacia la creación de más realidad. Pero nadie sabe «todo», la realidad se esquematiza en unidades simbólicas que representan la experiencia que el sujeto ha tenido. Sabiendo cómo el ser humano interpreta el mundo sabemos mucho de su naturaleza como individuo. Y también de los valores medioambientales y sociales conforme a los cuales se realiza la simbolización.

Con el ser humano aparece la Filosofía. Pero no una filosofía entendida como una teoría entre otras teorías, sino el filosofar como ansia de saber. Es un sentido socrático el que estamos atribuyendo al filosofar: como superación de los propios límites que atribuimos a nuestra ignorancia y al profundo deseo de saber cada vez más; nos referimos especialmente a la sabiduría que necesitamos para desarrollar con plenitud la propia vida. De esa búsqueda no hay nadie que esté excluido puesto que, de una forma u otra, a todos concierne, cuanto menos, su propia existencia.

Puede decirse por ello, porque el ser humano no puede asumir toda la realidad, que vive en mundos construidos o, si se quiere para no confundir el término con otras corrientes de pensamiento en boga más radicales, interpretados o simbolizados. Es en ellos donde tiene que realizar el esclarecimiento de su existencia. Un esclarecimiento que no necesariamente es consciente: asume en su infancia un entorno que es muy variable para cada individuo y que tiende a dar por supuesto hasta ciertos momentos críticos de la vida. Y lo da tanto en sus aspectos positivos como frustrantes ya que la satisfacción real de todos los instintos es imposible para cualquier ser vivo. El símbolo implica positividad y negatividad y con ellas debe el sujeto convivir. El símbolo se convierte en criterio para la acción. En tanto que cada sujeto recibe una ins- 
tancia de realidad, y tiene una corporalidad diferente y una psique diferente, puede hablarse de que cada sujeto es distinto y vive en mundos simbólicos no del todo compartidos con los demás. Evidentemente no son universos privados en tanto que existe mucho mundo común, pero debe decirse al mismo tiempo que no existe una absorción de toda la individualidad -como experiencia de realidad- en el grupo humano en el que se vive. Ello convierte, en mayor o menor proporción, a cada psique en una psique diferente de las otras.

\section{LA FUNCIÓN DE LA FILOSOFÍA EN LA VIDA HUMANA}

La función que Jaspers atribuye a la Filosofía en su Psicopatología General recuerda a otras ideas que serán desarrolladas más tarde por Heidegger. No en vano el trato que mantuvieron hasta la llegada de la Segunda Guerra Mundial fue intenso desde el año 1920, fecha en la que se conocieron en casa de Husserl. Consta en la actualidad un catálogo de 155 cartas (desde 1920 hasta el año de la muerte de Jaspers en 1969) en las que, en las primeras, en el deseo de amistad, se mantiene lo que ellos llaman una comunidad de lucha filosófica por el esfuerzo del pensar. Creían que juntos podrían volver a hacer que la Filosofía desempeñase la función que había tenido en otros tiempos, para ellos dos, mejores. Tiempos en los que no se confundía el pensamiento con el parloteo, sino en los que se buscaba un saber de auténticos principios. Un saber en los que la Filosofía no se reducía a un conjunto de teorías filosóficas sino que consistía en el esfuerzo humano por pensar un ser inobjetivable. Toda teoría es un esfuerzo por pensar lo real y la ciencia misma, para hacerlo, excluye esferas de realidad y se reduce al ámbito de la objetividad. Pero supondría una escasa comprensión de la ciencia creer que con ella se abarca la realidad total.

En el parágrafo tercero de la sexta parte de su obra, Jaspers estudia las relaciones entre psiquiatría y filosofía. Respecto a lo que entiende por Filosofía destaco las siguientes afirmaciones que pueden, como él hace explícitamente, recogerse en cinco puntos de los cuales citaremos únicamente el primero y el quinto por mor de brevedad:

1. El ser mismo no es captable adecuada y suficientemente en ninguna objetividad, sino que es lo siempre abarcativo inobjetivo, desde donde se nos presenten estos objetos para la conciencia, en la escisión-sujeto-objeto. (1977: 876).

Con ello afirma que la totalidad no es abarcable. Cualquier intento de teoría omnicomprehensiva queda siempre en mera tentativa o, a lo sumo, en programa de investigación. Esto funda el hecho de la trascendencia del sujeto respecto de su propia objetividad y, en consecuencia, en la temática que abordamos, hace posible la cura y el cuidado: si el sujeto quedara convertido en cosa, si diéramos completamente razón de él, no pasaría, como pudiera suponerse, 
que pudiéramos curarlo. Ocurriría exactamente lo contrario porque para salir del estado de objeto el ser humano necesita seguir siendo un sujeto trascendedor. Por decirlo de una forma gráfica, así como existe una «dinámica» humana no existe una «estática» del ser humano a no ser en la pura teoría. Quien no avanza, retrocede. Quien no actúa, muere.

5. El defecto básico de nuestro conocer es la inversión de pensamientos filosóficos en supuesto saber objetivo acerca de algo. Esa inversión acontece en todos los pensamientos de lo cotidiano como en las ciencias. Una de esas inversiones es la del esclarecimiento existencial en saber psicológico, la de la libertad en un factor del existir empírico, es la falsa tematización del ser humano en total. Pues esto permanece siempre lo abarcativo que somos, y retrocede ante toda objetivación o plastificación también en las totalidades más amplias, que se vuelven contenido del conocimiento. Pero lo abarcativo no podemos pensarlo involuntariamente como objetos en las categorías del acontecer, de la causalidad, de la substancia, de la fuerza, etc., aunque nos sirvamos de tales expresiones en el lenguaje circulante, que hay que retirar de inmediato (1977: 877).

La Filosofía se convierte, de esa forma, no en determinación de lo que se sabe científicamente, es decir, de lo objetivo. Y eso objetivo es perfectamente posible alcanzarlo en el grado de finitud de su complejidad y de la finitud del entendimiento humano a través de la ciencia. Ahora bien, en la psicopatología, ninguna teoría filosófica debe plantearse como aquello que recoge lo objetivo humano en el sentido de intentar agotar lo humano. No es que lo humano no obedezca a causas, que en parte lo hace, sino que la libertad consiste en trascender el concepto de causalidad lineal y obedece más bien a otro tipo de comportamiento regulado que nada tiene que ver con la objetividad natural. Así como las órbitas de los planetas se comportan de forma bastante constante y en la aprehensión de esa linealidad consiste su saber objetivo, el operar del ser humano no obedece a esa misma operatividad sino que tiene la posibilidad permanente de romper su rutina de actuación y de hacerlo tanto de forma azarosa como regida por principios que se ajustan a la racionalidad práctica en busca de una resolución eficaz de los problemas que puedan presentársele.

La Filosofía, más que saber objetivo, tiene la función en la vida humana de orientar hacia fines conforme al saber que el sujeto posee, es decir, conforme al el conjunto de simbolizaciones en las que consiste lo que podríamos llamar su «mundo construido». Y es que la simbolización no es necesariamente un saber acerca de lo permanente y de lo inalterable sino que está abierta a las nuevas experiencias y al diálogo con los otros sujetos. De esta manera, puede decirse, el sujeto humano está siempre en una permanente «recomposición simbólica» desde su posición inicial en el mundo. Su vida consiste precisamente en eso y, si no lo hace, los automatismos y los hábitos pueden volverse 
demasiado rígidos y conducirle a problemas con su propio bienestar mental o con el bienestar mental de aquellos que le rodean.

\section{ESTAR SANO Y ESTAR ENFERMO.}

LA FUnCiÓN DE LA PSICOPATOLOGÍA EN LA ANTROPOlogía FilosófiCA.

Si algo deja claro Jaspers en su obra es su alejamiento de todo dualismo que lleve, en medicina, a un modelo iatromecánico reductivamente materialista o a un espiritualismo estéril. Pero considero que no está mal que pensemos durante unos momentos en las posiciones dualistas puesto que han configurado gran parte del pensamiento occidental. En ellas se ha vertido tanto esfuerzo que no resultaría justo pasar delante de ellas sin tratarlas aunque sea someramente.

La distinción entre cuerpo y alma (mente) tiene una larga tradición histórica que es comprensible que se formulara en esos términos. Por un lado, puede existir cuerpo sin alma como de hecho se da en el reino mineral (posturas hylozoistas aparte) o como se da en el caso de la muerte: un cuerpo que ya no respira, que tuvo pero que ya está carente de aliento (que es, por cierto, la raíz de donde vienen las palabras psique y pnêuma). Por otra parte, la influencia del cuerpo sobre la mente es también evidente: ingerir demasiado alcohol o un golpe en la cabeza puede disminuir drásticamente los niveles de conciencia. Hoy en día existe, además, control farmacológico de esos niveles. Es también claro que lo psíquico influye en la corporalidad: un estado emocional cualquiera despierta consecuencias somáticas; incluso se afirma en algunas escuelas que ciertas enfermedades del aparato digestivo o de la piel están asociadas a niveles de estrés. Quedaría por saber si existe una separabilidad de la mente y si esa separabilidad de la mente del cuerpo implica inmortalidad o no. Pero eso es tarea para otro trabajo, aunque haremos alguna referencia a ello en las líneas siguientes.

Así como es evidente una unidad psicofísica, que es a la que Jaspers se suma, resulta problemático señalar las características «puras» tanto del cuerpo como de la mente. Desde el punto de vista del materialismo naturalista, el cuerpo es un mecanismo biológico que, si enferma, es cuestión de cambiar la pieza que falla o, si se debe a cuestiones humorales, hay que restablecer los niveles adecuados de humor para sanarlo. Ese es el modelo iatromecánico. Un modelo que, en tanto que excluye la mente, se topa con el problema de darle un sentido aunque solo sea a nivel fenoménico porque: ¿para qué aparece la mente si es inútil? Y si tiene un sentido, como creo que lo tiene, no se encontrará en los engranajes y poleas del cuerpo como Leibniz concluyó en su célebre argumento del molino de la Monadología. Por otro lado, como Descartes argüía en la segunda de sus Meditaciones, parece evidente que la mente es lo más importante del ser racional y que, así como puedo pensarme sin cuerpo 
no puedo concebirme sin mente si quiero dar razón profunda de la naturaleza que poseo. «Yo soy un ser pensante».

Para Jaspers, toda esta retórica argumental es necesaria pero no hace caer más que en falacias y en ambigüedades. Y la mejor forma de demostrarlo es reconocer que hemos avanzado bastante poco en la solución del problema. Hemos profundizado en los argumentos, hemos radicalizado en algunos casos las posturas, concebimos que es necesario un tipo de monismo que no sabemos todavía cómo encajar teóricamente, pero todo queda todavía, ante la seriedad de los argumentos que se esgrimen, en deseos de solución y no en solución en sí misma. Jaspers no entra a la llamada de estos argumentos. Concibe que desde donde hay que partir es desde la unidad biopsíquica del sujeto - del sujeto orgánico vivo- que es de lo único que podemos estar seguros y que se convierte en el objeto mismo de la medicina. Jaspers es, en este sentido, pragmático y no pretende resolver problemas de la antropología que se remontan a miles de años. Se ocupa del sujeto vivo y observa en él una triple dimensión orgánica, psíquica y espiritual en interacción sin que quiera determinar con su bisturí de cirujano dónde empieza una y acaban las otras. Tan solo ve -y eso ya es bastante- que un defecto orgánico causa enfermedad, que un defecto de estructura psíquica también la causa y que un sistema de valores repercute en ambos constituyendo un todo saludable o un sujeto enfermo. Los fuertes sistemas de retroalimentación entre los tres principios constitutivos de la subjetividad humana hacen que su unidad derive en un todo de acción que adquiere unos u otros sentidos: sentidos de salud o sentidos de enfermedad.

No hay, y al afirmar esto sé que me muestro muy atrevido, cuerpos enfermos, psiques enfermas o espíritus enfermos. Hay personas enfermas por alguna o algunas causas, pero considero claro que padecer una enfermedad orgánica afecta de múltiples maneras a la psique y a los entornos valorativos, así como todas las combinaciones posibles que puedan darse entre esos tres elementos. Es verdad que la medicina convencional atribuye la enfermedad únicamente a las causas orgánicas y que parecería que se diera una cierta relación causal unidireccional entre causa orgánica y repercusión psíquica. Pero hay otras escuelas, las llamadas de medicina psicosomática, que advierten de que esa unidireccionalidad no es real y que bien puede verse cómo la dirección inversa, la enfermedad psíquica, repercute en problemas de índole orgánica.

Hay aún otro problema que merece la pena ser tratado: si todos los seres humanos nacen en un entorno sociocultural que les ofrece de nacimiento un conjunto de valores: ¿qué pasaría si esos valores fueran perversos? ¿Puede decirse que hay sociedades enfermas por el conjunto de valores vitales con las que conciben el mundo e imponen incluso de forma inconsciente a sus ciudadanos? Incluso más, las estructuras del conjunto son tan fuertes que nada pueden los sujetos hacer para luchar en contra de ellas y cambiarlas como un todo. $\mathrm{Y}$ 
parece ser que una sociedad cuyo valor último es la competición y su objetivo la productividad engendra niveles de estrés demasiado altos para poder decir que sus ciudadanos están sanos. Incluso más, como si fuera una novela distópica, el propio sistema oculta sus raíces en los buenos consejos acercándose a un paternalismo buenista totalitario que todos aceptan sin criticar: hay que hacer deporte, llevar una alimentación saludable, no fumar, moderar el consumo de alcohol, estar delgado, ser guapo, aprender inglés, estar informado, etc. Pero a nadie se le ocurre atacar los valores de fondo que se mantienen manifiestamente inalterables. Esos niveles de no-vivir son realmente patogénicos aunque nos hayamos acostumbrado demasiado a vivir según ellos. Lo que se considera virtud social puede dar lugar a individuos que interpretan esos valores de forma demasiado rígida y que, en consecuencia, enfermen. También puede ocurrir que las otras estructuras intenten compensar la frustración y se caiga en claras patologías y en trastornos evidentes de conducta.

Es por ello, en resumen, que la función de la psicopatología en la Antropología Filosófica va más allá de constituir una mera anécdota. Supone reconocer que la media sociológica enferma va más allá de ser una pequeña proporción y que abarca grandes masas de población. Los valores con los que se mueven no son los mejores para construir existencias plenas y felices. Así como se está mejorando e invirtiendo mucho en medicina convencional y en farmacología psiquiátrica, se está invirtiendo y mejorando mucho en neurociencia para estudiar la estructura del cerebro en aras a dar solución a las enfermedades neurodegenerativas y de base orgánica cerebral, también se está invirtiendo mucho en tratamientos de terapia múltiple para solucionar los problemas de comunicación y de trastornos mentales. ¿Pero se está invirtiendo en cambiar los valores existenciales? ¿Se le recuerda al ser humano que la felicidad es una obligación para consigo mismo y los demás? Hay algunos que pueden escapar de la vorágine que busca el éxito y la excelencia a costa de cualquier cosa. Pero la mayoría no puede. El sistema los absorbe de tal manera que viven de la mañana a la noche pegados un teléfono móvil y sufriendo pacientemente las reprimendas del encargado de turno. Si eso no es una sociedad enferma que me digan cuál lo es. Y si la antropología filosófica no puede o no debe señalarlo y, si alguien me convence de que no debe o no puede hacerlo, estoy dispuesto a cambiar de ámbito de estudio.

\section{Conclusión}

¿Debe la Antropología Filosófica convertir a la Filosofía de la Psicología y a la Filosofía de la Psiquiatría en objetos propios de su estudio? A través de la obra de Jaspers he intentado ver que se constituye como una necesidad ya que una categoría básica de lo humano es estar sano o es estar enfermo y he señalado los elementos de su estructura que causan la salud o la enfermedad. 
Una excelencia humana que no implique modelos de vida saludable y actitudes vitales positivas es una triste excelencia humana. Por ejemplo, el modelo de ser humano virtuoso puede ser apasionante como mostró Aristóteles. Pero el virtuoso, por sí mismo, puede ser un perfecto desgraciado si funda su virtud en el deber por el puro deber hasta incluso derrumbarse o quebrarse existencialmente. Y lo mismo ocurre con el placer, las riquezas o la fama de forma aislada. No se consigue la felicidad con obsesiones desestructuradas. En resumidas cuentas, lo que persigue la psicopatología y lo que la hace interesante para la Antropología Filosófica es someter al individuo y a los grupos en los que vive a un proyecto de sanación que les conduzca a la plenitud existencial. Con ello conectamos con la cuestión de la antropología como análisis existencial, pero eso es ya un tema diferente que no fue expresamente desarrollado por Jaspers en sus obras médico-filosóficas sino por aquel con el que compartió una fuerte amistad, truncada por la guerra, durante algunos años: Martin Heidegger.

\section{REFERENCIAS BIBLIOGRÁFICAS}

ARISTÓTELES, Sobre el alma. Gredos. Madrid, 1988.

DESCARTES, R. Meditaciones metafísicas. Alfaguara. Madrid, 1977.

, Tratado sobre el hombre. Editora Nacional. Madrid, 1980.

FUCHS, TH. et al. (Eds.) Karl Jaspers. Phänomenologie und Psychopathologie. Alber. Freiburg, München, 2013.

FULFORD, K. W. M et al. (Eds.) The Oxford Handbook of Philosophy and Psychiatry. OUP, 2013.

HEIDEGGER, M. Ser y Tiempo. Madrid. Trotta, 2003.

HEIDEGGER, M., K. JASPERS Correspondencia. Madrid. Síntesis, 2003.

JASPERS, K. Allgemeine Psychopatologie. Springer. Berlin, 1973.

, Psicopatología General. Beta. Buenos Aires, 1977.

, General Psychopathology. Johns Hopkins UP, 1997.

, Escritos psicopatológicos. Gredos. Barcelona, 1977.

LEIBNIZ, Monadología. Aguilar. Buenos Aires, 1972.

ORTEGA BEVIÁ, F. Trastornos emocionales y mentales en el niño. Agathos Ediciones. Barcelona. 2017.

PADIAL, J.J. Filosofía de la Psiquiatría. La convergencia entre Fenomenología y Psiquiatría en los siglos XX y XXI. Málaga, 2015. Pro manuscripto.

SCHELER, M. El puesto del hombre en el cosmos. Losada. Buenos Aires, 1974.

THAGARD, P. (Ed.) Philosophy of Psychology and Cognitive Science. Elsevier. Amsterdam, 2007. 
Francisco Rodríguez Valls es Profesor Titular de Filosofía en la Universidad de Sevilla.

Linea de investigación:

Antropología Filosófica en sus relaciones interdisciplinares con las ciencias naturales y humanas.

Publicaciones recientes:

Orígenes del hombre. La singularidad del ser humano (Biblioteca Nueva. Madrid, 2017. 208 páginas).

El sujeto emocional. La función de las emociones en la vida humana (Thémata. Sevilla, 2015. 190 páginas).

«Ser humano y naturaleza», en Guía Comares de Filosofia de la Naturaleza, Juan Arana (Editor) (Ed. Comares. Granada, 2016).

«The emotional subject in Philosophy of Psychology: the cases of Anxiety and Angst», capítulo de libro editado por Wenceslao J. González (Walter de Gruyter. Boston/Berlin, 2018).

Correo electrónico: rvalls@us.es. 